\title{
Effects of circuit-type resistance training on industrial opiate induced neurotransmitter disruption and performance changes of previously addicted men
}

\author{
Hamid Arazi, Seyedeh Shiva Dadvand \\ Department of Exercise Physiology, Faculty of Sport Sciences, University of Guilan, Rasht, Iran
}

\section{Summary}

Study aim: The aim of this study was to examine the effects of an 8-week circuit-type resistance training program on performance changes and neurotransmitter disruptions induced by industrial opiate in previously addicted men.

Materials and methods: Thirty industrial opiate addicted men volunteered to participate in this study and were randomly assigned to experimental $(n=15)$ and control groups $(n=15)$. The subjects in the experimental group performed circuit-type resistance training for 8 weeks, 3 days a week, with 40-75\% of one-repetition maximum (1RM), while the control group did not perform any training. Before and after the training period muscular strength (1RM of bench press) and muscle endurance (sit-ups), flexibility (sit-and-reach), body fat percentage, waist-to-hip ratio (WHR) and cardio-respiratory endurance were measured. In addition, blood samples were drawn $24 \mathrm{~h}$ before and after 8 weeks of training to analyze serum levels of serotonin, dopamine, and endorphins.

Results: In this study, 8 weeks of circuit-type resistance training led to significantly higher serum levels of serotonin, dopamine, and endorphins, cardio-respiratory endurance, muscular strength and endurance in the experimental group compared to controls $(\mathrm{P}<0.05)$, while flexibility, body fat percentage and WHR did not differ significantly $(\mathrm{P}>0.05)$.

Conclusions: In conclusion, circuit resistance training can improve the serum levels of serotonin, dopamine, and endorphins, as well as indicators of health-related performance previously industrial opiate addicted men.

\section{Keywords: Serotonin - Dopamine - Endorphins - Performance adaptations - Rehabilitation - Treatment period}

\section{Introduction}

It has been well documented that drug addiction has a great negative influence on society and substance use disorders (SUD) are a major problem of public health $[9,47]$. SUD and behavioral addictions are destructive conditions for society that lead to severe challenges for physicians [11]. Drug addiction is defined as a complicated brain disorder that affects biological and environmental behaviors [9] and involves body and mind like other mental disorders. This problem is characterized by an individual's desire to consume the drug, even with the knowledge of its fatal consequences [11]. After drug rehabilitation, the reuse of the substance is one of the critical problems in the treatment process. It appears that $70 \%$ of addicts start to reuse the drug after one-year rehabilitation
[42]. In addition, chronic methamphetamine abuse reduces the transport density of dopamine into the corpus striatum and lesser in the frontal cortex, resulting in the drainage of dopamine terminals in the corpus striatum [28]. Similarly, the amount of serotonin transport is reduced in other parts of the brain [39]. It seems that increases in mental stimuli by SUD inhibit dopamine transmitters, increase dopamine release [1], inhibit serotonin reabsorption and increase them in the extracellular space [27]. Methamphetamine use disorder is associated with a striatal dopaminergic deficiency, which is associated with poor treatment outcome. Determining these ways could play an important role in the management and rehabilitation process [20].

Exercise has an effect on levels of serotonin and dopamine transmitters [38]. Dopamine neurotransmitter is formed in the dopaminergic axon terminal [37] and plays an important role in control of motivation, learning positive 
and negative affairs, choosing actions to acquire good things and avoid bad things [18], adjusting movements, recognizing motivation, and feeling of pleasure [37]. The monoamine neurotransmitter serotonin (5-HT) also plays an important role in regulating various physiological functions such as sleep or wakefulness, appetite, nociception, mood, stress, and maternal or sexual behavior. Peripheral 5-HT is synthesized from tryptophan by tryptophan hydroxylase in enterochromaffin cells of the gastrointestinal tract [9]. Previous studies showed that long and short-term physical exercise can result in changes in neurotransmitter systems [24]. On the other hand, physical activity and exercise have synergetic effects and can be used for the management of SUD and improvement of status in addicted people [48]. O'dell et al. (2012) examined the effect of exercise on the recovery of dopaminergic and serotonergic terminals' damage in methamphetamine-addicted mice and found that doing 7-day exercise after rehabilitation significantly changed the levels of serotonin, dopamine and its receptors in some areas of the brain [30].

It appears that half an hour after starting exercise or physical activities, the beta endorphin-derived morphine secretion in the brain is increased and affects the brain receptors, which results in experiencing pleasant and euphoric feelings the as same as drug use [8]. $\beta$ endorphin highly depends on the pseudo-opioid receptor $(\mu)$. The $\mu$ receptors are the main receptors of morphine activity and are presynaptic receptors that inhibit the release of neurotransmitters, increase the release of dopamine pathways, and lead to more dopamine release and pain relief [1]. Physical exercise could increase $\beta$-endorphin levels and these elevations remained for 2 days after exercise [27].

Today, addiction is known as a global problem facing all countries [35]. Substance use disorder and drug dependence have become one of the major problems in the world and, after the nuclear crisis, population explosion, and environmental pollution, have ranked as the fourth global human crisis [21]. In Iran, the number of drug users is estimated to be between 1.8 and 3.3 million people and opiate is the most used substance [40]. Studies show that 20 to $90 \%$ of drug addicts experience relapse [40].

Exercise may also reduce drug abuse in the human population [24]. Exercise leads to activation of the brain system similar to drug use such as cocaine through an increase in dopamine and receptors and creates neuronal-hormonal compatibility [25]. Drug use such as methamphetamine leads to an increase in the reaction between oxygen and nitrogen and damage to mono-aminergic terminals [38]. Therefore, long-term exercises induced increases in endogenic antioxidant enzyme activity [44]. Several studies have shown that exercise activates the same systems that can also be activated by morphine and other opioids, and releases endogenous opiate peptides, in particular, $\beta$-endorphin, and elevates the threshold of pain
[26]. Because exercise could be effective in increasing the serum levels of serotonin, dopamine, and endorphins, the hypothesis of the effects of an 8-week circuit-type resistance training program on performance changes and neurotransmitter disruptions induced by industrial opiates in previously addicted men is raised.

Although some studies have been performed on the effect of aerobic and combined exercises on healthy and unhealthy subjects, to the best of our knowledge no study has evaluated the effect of circuit-resistance training on neurotransmitters in industrial substance-addicted men. It is well documented that the circular resistance exercises have many cardio-respiratory and muscular benefits. The effects of circular resistance exercises were conclusively confirmed in healthy subjects, but due to the difficulty of performing the exercises in patient populations, especially addicted people, no comprehensive studies have been conducted on the efficiency of circular resistance exercises on addicts. In order to improve the treatment process and rehabilitation in society, especially among the young generation, research on this subject is vital. Therefore, the aim of this study was to examine the effects of an 8-week circuit-type resistance training program on performance changes and neurotransmitter disruptions induced by industrial opiates in previously addicted men.

\section{Materials and methods}

\section{Participants}

Thirty industrial opiate addicted men volunteered to participate in this study and were randomly assigned to two groups: the experimental group (EG; $\mathrm{N}=15$, age $31.2 \pm 4.8$ years, height $173.8 \pm 2.6 \mathrm{~cm}$, weight $73.9 \pm 4.5 \mathrm{~kg}$ and BMI $\left.24.4 \pm 1.8 \mathrm{~kg} / \mathrm{m}^{2}\right)$ and the control group (CG; $\mathrm{N}=15$, age $30.2 \pm 5.0$ years, height $175.4 \pm 3.7$ $\mathrm{cm}$, weight $73.7 \pm 5.5 \mathrm{~kg}$ and BMI $\left.23.9 \pm 1.3 \mathrm{~kg} / \mathrm{m}^{2}\right)$. Subjects were informed as to the experimental procedures and signed informed consent statements and medical history forms in adherence with the human subjects' guidelines of the university before any data collection. The study was conducted in accordance with the Declaration of Helsinki and was approved by the research committee of the institute (Protocol ID: 934.95.3043). Before initiation of the study, subjects had to fulfil some inclusion criteria including: 1) no use of narcotics or cigarettes during the study period, 2) the drug rehabilitation period between 3 to 6 months, 3) at least 3 years of addiction history, 4) no history of psychiatric, cardiovascular, thyroid or gastrointestinal diseases, 5) no history of diabetes, AIDS or hepatitis, 6) no history of musculoskeletal injuries and 7) not participated in a structured resistance training program for at least 1 year. 


\section{Study design}

The present study has a longitudinal research design. One week before the start of the training period, all subjects reported to the laboratory for familiarization with training and testing procedures. During the familiarization session, subjects' initial characteristics such as age, height, weight, and BMI were measured. After completing these measures, muscular strength, endurance, flexibility, WHR, body fat percentage, and cardio-respiratory endurance were measured on two non-consecutive days (i.e., day 1 strength and endurance, and day 2 flexibility and cardiorespiratory endurance) and were always administered in the same order, at the same time of the day. Subjects in EG performed an 8-week circuit-type resistance training program while the CG did not perform any resistance training program and blood sampling was performed 24 hours before the first and 24 hours after the last training session for the analysis of blood serum levels of serotonin, dopamine, and endorphins. Participants were instructed to maintain their normal caloric intake throughout the duration of the study.

\section{Testing procedures}

All testing sessions were conducted at the same time of day to account for diurnal effects that have typically been noted when assessing blood samples and performance measures. Before performance testing, each subject performed ten minutes of standard warm-up.

\section{Anthropometric measures}

Subjects' height was measured using a wall-mounted stadiometer (RACE, China) recorded to the nearest $0.1 \mathrm{~cm}$. Body mass was measured to the nearest $0.1 \mathrm{~kg}$ using a digital scale (Camry, China). The body mass index (BMI) was determined by dividing body mass by the square height of the subject (kilograms per square meters). To determine the body fat, skinfold thickness was obtained with a caliper (YAGAMI, Eiyoken, Japan) at the chest, abdomen, and thigh following the procedures previously described. A 3-site skinfold equation was used to estimate percent body fat using the Jackson and Pollock equation [20].

\section{Performance measures}

The cardio-respiratory endurance was determined by the Rockport Walk Test. In the test, the subject was asked to walk one mile $(1.6 \mathrm{~km})$ as fast as possible. The maximum oxygen consumption was calculated using this formula [18]:

$\mathrm{Vo}_{2 \max }\left[\mathrm{min}^{-1} \cdot \mathrm{ml} \cdot \mathrm{kg}^{-1}\right]=100.5+(8.344 \times$ gender $)-$ $(0.1636 \times$ weight $)-(1.438 \times$ time $)-(0.1928 \times$ heart rate $)$ "Gender: male 0; female 1"; "weight = kg"; "time = time of 1 mile jogging"; "heart rate = final hear rate".
Strength of subjects in the bench press exercise was measured as the upper body strength with a few trials of the one-repetition maximum (1RM) test as previously described. Subjects were allowed to perform a maximum of 8 repetitions during the bench press, and the equation of Brzycki [7] was used to determine 1RM.

$$
\begin{aligned}
1 \mathrm{RM}= & \text { Displaced weight }[\mathrm{kg}] /(1.0278-[\text { number } \\
& \text { of repetitions to fatigue } \times 0.0278])
\end{aligned}
$$

To measure muscular endurance of the abdomen and flexibility, sit-up and sit-and-reach tests were used. The sit-up estimates the resistance strength of the muscles of the abdomen and of the hip flexors.

The participants lay down on a mat in a supine position with their knees flexed $90^{\circ}$, their feet pressed on the ground, and their hands on their thighs. To complete the tests, the participants had to slide their hands along their thighs to their kneecap and then return to the initial position. The aim was to do the maximum number of repetitions in 30 seconds [2].

In the sit-and-reach test, the subject sits in front of a sit-and-reach testing box, where the feet meet the testing box at the $23 \mathrm{~cm}$ mark of the measuring scale. The subject was instructed to reach forward, with palms down and one hand on top of the other along the measuring scale of the testing box. The reach was repeated three times with a maximum reach on the third repetition held for 1 second. The distance of the fourth reach was used as the absolute measure for the sit-and-reach test. A 1-minute bent-knee sit-up test was used to assess abdominal muscular endurance.

\section{Blood sampling}

To analyze serum levels of serotonin, dopamine and endorphin, a 5-mL blood sample was collected at rest between 8:00 and 9:00 a.m. $24 \mathrm{~h}$ before and after resistance training and after $12 \mathrm{~h}$ of fasting by venipuncture of an antecubital vein; the resultant samples were allowed to clot at room temperature for 15 minutes and then centrifuged at $1500 \times \mathrm{g}$ for 10 minutes. The serum was then pipetted into polyethylene blood tubes and frozen at $-80^{\circ}$ $\mathrm{C}$ for subsequent analysis. The serum serotonin (DLD, Germany), dopamine (Glory Science Human, USA) and endorphin (Cusabio Biotech, Japan) levels were measured using commercially available kits with a sensitivity of $\sim 1$ $\mathrm{pg} / \mathrm{ml}$ and $<6.5 \%$ coefficient of variation.

\section{Resistance training program}

In this study circuit-type resistance training programs were performed 3 times a week, including 70-85 minutes (e.g., 15 minutes warm up, 50-65 minutes resistance training and 5 minutes cool down) for 8 weeks. The subjects in EG performed a resistance training program with 6 exercises for 1 set of each exercise (e.g., leg press, lat pull 
down, hip abduction, bench press, knee flexion, dumbbell curl) and return to the first exercise and this approach was performed 2 times each training session for 4 weeks (Table 1). In addition, at weeks 4 to 8 , the subjects performed 8 exercises (leg press, lat pull down, hip abduction, bench press, knee flexion, dumbbell curl, standing calf raises, and triceps pushdown) of circuit type. The intensity of resistance exercise progressively (i.e., $5 \%$ weekly) increased throughout 8 weeks of training. The subjects were tested every 2 weeks to update $1 \mathrm{RM}$ and resistance training load. All the training sessions were supervised, and training diaries were maintained for each subject.

\section{Statistical analysis}

All data are expressed as the mean \pm standard deviation (SD). In the present study, the Shapiro-Wilk test was used to evaluate the normal data distribution. To determine the effects of intervention on performance and serum blood variables, a $2 \times 2$ ANOVA was applied. When a significant
F value was achieved, the Tukey post-hoc test was performed to determine the pairwise differences between the means. In this study, SPSS V.20 was employed to perform the statistical analysis. The level of significance was set at $\mathrm{P}<0.05$

\section{Results}

There were significant increases in serum serotonin $(\mathrm{P}=0.001)$, dopamine $(\mathrm{P}=0.001)$, endorphin $(\mathrm{P}=0.001)$, cardio-respiratory endurance $(\mathrm{P}=0.001)$, WHR $(\mathrm{P}=0.041)$ and muscular endurance $(\mathrm{P}=0.001)$ and strength $(\mathrm{P}=0.001)$ for the EG after training (Fig. 1). However, no significant changes were observed in flexibility $(\mathrm{P}=0.140)$ and body fat percentage $(\mathrm{P}=0.317)$.

The results showed no significant difference between before and after values of control group in terms of the serum levels of serotonin $(\mathrm{P}=0.847)$, dopamine $(\mathrm{P}=0.802)$,

Table 1. Circuit Resistance training protocol

\begin{tabular}{lcc}
\hline & Week 1 to 4 & Week 5 to 8 \\
\hline Number of exercises & 6 & 8 \\
Number of circuits & 2 & 2 \\
Number of repetitions & $8-10$ & $10-12$ \\
Exercise intensity & $40-55 \%$ of $1 \mathrm{RM}$ & $60-75 \%$ of $1 \mathrm{RM}$ \\
Rest between exercises & 30 seconds & 30 seconds \\
Rest between circuits & 3 minutes & 3 minutes \\
\hline
\end{tabular}

$1 \mathrm{RM}$ - one repetition maximum.

Table 2. Changes in the performance and anthropometric variables before and after training for the experimental and control groups (mean $\pm \mathrm{SD})$

\begin{tabular}{llcc}
\hline Variable & & Experimental $(\mathrm{n}=15)$ & Control $(\mathrm{n}=15)$ \\
\hline $\mathrm{VO}_{2 \mathrm{max}}\left[\mathrm{ml} \cdot \mathrm{kg}^{-1} \cdot \mathrm{min}^{-1}\right]$ & Before & $30.80 \pm 1.01$ & $30.40 \pm 1.05$ \\
& After & $35.86 \pm 1.40^{*}$, & $30.60 \pm 1.05$ \\
Sit-ups $[\mathrm{reps} / 30 \mathrm{sec}]$ & Before & $16.53 \pm 2.13$ & $15.33 \pm 1.79$ \\
& After & $19.00 \pm 2.32^{*}$, & $14.33 \pm 1.49$ \\
1RM bench press $[\mathrm{kg}]$ & Before & $35.80 \pm 2.17$ & $32.00 \pm 0.75$ \\
& After & $50.00 \pm 1.06^{*} \dagger$ & $31.00 \pm 0.84$ \\
Sit-and-reach test $[\mathrm{cm}]$ & Before & $35.93 \pm 7.71$ & $34.46 \pm 5.93$ \\
& After & $39.80 \pm 6.89$ & $33.26 \pm 6.64$ \\
Body fat $[\%]$ & Before & $21.46 \pm 1.25$ & $20.40 \pm 2.02$ \\
WHR & After & $21.40 \pm 1.05$ & $21.33 \pm 1.91$ \\
& Before & $0.78 \pm 0.14$ & $0.79 \pm 0.16$ \\
\hline
\end{tabular}

* - Denotes significant differences between before and after training values $(\mathrm{P}<0.05) ; \uparrow$ - Denotes significant differences between the experimental and control groups $(\mathrm{P}<0.05)$; WHR - waist-to-hip ratio; 1RM - one repetition maximum. 

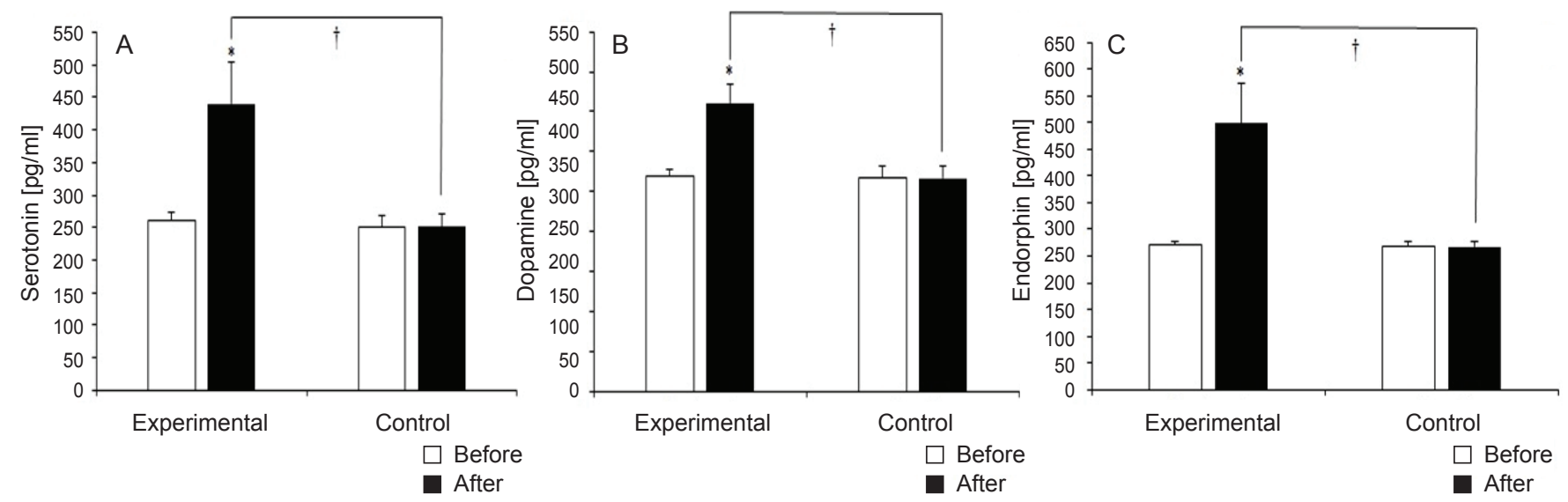

Fig. 1. Changes in Serotonin (A), Dopamine (B), and Endorphin (C) for the experimental and control groups between before and after training (mean $\pm \mathrm{SD})$; $*$ denotes significant differences between before and after training values $(\mathrm{P}<0.05) ; \dagger$ denotes significant differences between the experimental and control groups $(\mathrm{P}<0.05)$

endorphin $(\mathrm{P}=0.340)$, cardio-respiratory endurance $(\mathrm{P}=0.684)$, flexibility $(\mathrm{P}=0.525)$, WHR $(\mathrm{P}=0.509)$, and body fat percentage $(\mathrm{P}=0.063)$. However, there was a nonsignificant reduction in muscular endurance $(\mathrm{P}=0.1)$ and strength $(\mathrm{P}=0.2)$ (Table 2$)$.

\section{Discussion}

The aim of this study was to examine the effects of an 8-week circuit-type resistance training program on performance changes and neurotransmitter disruptions induced by industrial opiates in previously addicted men. The results showed that circuit resistance training significantly increased the serum levels of serotonin, dopamine, endorphins, cardio-respiratory endurance, body fat percentage, muscle endurance, and strength, while no significant effects were observed in flexibility, body fat percentage or WHR.

The results of the present study also demonstrated that circuit resistance training resulted in an increase in the serotonin and dopamine level in the experimental group compared to the control group. In line with our findings, Robertson et al. (2016) aimed to investigate the effect of the training program on the amount of dopamine in addicted men and women. The study showed that exercise can increase the amount of dopamine in the experimental group [36]. The effects of aerobic and resistance exercise on neurotransmitters and cardiovascular responses were investigated by Arazi et al. (2017). The results of the study showed an increase in blood serotonin and dopamine levels after aerobic and resistance exercise [4]. Arazi et al. (2017) evaluated the effect of an 8-week aerobic exercise program on serotonin plasma levels and depression in 20 methamphetamine-addicted men during rehabilitation and demonstrated a significant increase in serotonin levels in the treatment group compared to controls [3]. Valim et al. (2013) evaluated the effect of strength and aerobic exercise on serotonin serum level (5HT) and its main acid (5HIAA) and reported that aerobic exercises increased 5HT and 5HIAA levels [46].

Smith et al. carried out a study on female rats and observed a significant effect of resistance training on the reduction of heroin consumption. Resistance training leads to a decrease in mRNA expression of mu-opioid and D1, D2, and D3 receptors in nuclei of NAc. Resistance exercise increased mRNA expression of dopamine D5 receptors in the NAc shell and increased mRNA expression of brain-derived neurotrophic factor (exons I, IIB, IIC, IV, VI, IX) in the NAc core. Resistance exercise decreases the positive reinforcing effects of heroin and produces changes in opioid and dopamine systems in the NAc of heroinexposed rats [41].

Exercise may also reduce drug abuse in the human population [24]. On the other hand, Lynch et al. showed that exercise leads to activation of the brain system similar to drug use such as cocaine through an increase in dopamine and receptors. Therefore, exercise could be used as a protective way against inhibition of relapse to drug use and to create neuronal-hormonal compatibility [25]. Fontes et al. (2011) evaluated the effect of exercise on amphetamineaddicted male rats and found overlapping of regular exercise with SUD [16]. O'dell et al. (2012) examined the impact of exercise on the serotonergic terminal damaged in addicted mice and found that exercise significantly improved the serotonin level and receptors in some parts of the brain [30]. Improvement of such damage through exercise by increasing the antioxidants could be a therapeutic effect because drug use such as methamphetamine leads to an increase in the reaction between oxygen and nitrogen and damage to mono-aminergic terminals [38]. Therefore, long-term exercise induced increases in endogenic 
antioxidant enzyme activity [44], and circuit resistance training could be a beneficial modality for increasing serotonin and dopamine levels.

The results of this study indicated that circuit resistance training induced significant increases in the endorphin level following the training period. In addition, increases in serum levels of beta-endorphin enhance dopamine levels and affect the brain reward system; also there is an increase in pain tolerance by affecting the $\mu$ receptor [34]. In fact, resistance exercise could increase the serum level of beta-endorphin by increasing available dopamine, resulting in an influence on the brain reward system and increasing tolerance by influencing $\mu$ receptors.

In addition, resistance exercise training increases the production of endorphins in the brain and therefore stimulation of the analgesic system in the brain and the spinal cord, thereby reducing the pain [23, 45]. Several studies have shown that exercise activates the same systems that can also be promoted by morphine and other opioids, and releases endogenous opiate peptides, in particular $\beta$-endorphin, and elevates the threshold of pain [26].

Moreover, it has been reported that exercise not only results in releasing endogenous pseudo-opioid peptides, but also it can play an important role in pain relief throughout various mechanisms including neutronization, increased patience, and mood moderation [43]. On the other hand, exercise and physical activity increased the production of beta endorphin-based natural morphine in the brain at half an hour after initiation of exercise by affecting the brain receptors similarly to opiates [8].

Cardio-respiratory endurance in the experimental group was increased significantly by circuit resistance training compared to the control group. In line with our findings, the results of Dolezal et al. (2014) showed that exercise leads to an improvement in the maximum oxygen consumption in the treatment group [12]. Banitalebi et al. (2010) reported that following drug rehabilitation, the choice of physical activity could increase the aerobic capacity of addicts [5]. An increase in oxidative enzyme activities, size, number, and volume of mitochondria, as well as the increase in the number of muscle fibers, muscle cross bridge, the myoglobin content of muscle, and an increase in the difference between oxygen of arterial blood and venous blood in both the heart and skeletal muscle lead to improving maximal oxygen consumption [22]. In resistance exercise, maximal oxygen consumption is increased by increasing capillary muscle density, blood volume, and hemoglobin.

Muscular strength was significantly higher in the experimental group than the control group after training intervention. Dolezal et al. (2013) examined the effect of 8-week resistance-endurance exercise training on methamphetamine-addicted subjects under treatment and reported statistically significant increases in strength and endurance performance [13].
Improvement in muscular strength by resistance training could have occurred via an increase in nervous impulses of motor units, size of type I and II muscle fibers, as well as an increase in anabolic hormones [17]. In resistance training, muscle contraction and hormonal changes result in activation of cascading pathways of gene expression and protein synthesis in MHC, resulting in muscle hypertrophy and strength gain [15].

In muscle endurance, the experimental group showed greater gains in sit-ups than the control group, which could be due to an increase in muscle contractile ability, increase in muscle cell energy production in aerobic pathways, and increase in mitochondrial biogenesis and type I muscle following circuit resistance training, which is in line with previous studies that reported a positive impact of a resistance training program on endurance performance [15]. Additionally, structural compatibility in muscle by the contraction process and postponing muscular tiredness play an important role in increased muscular endurance following resistance training [10]. Long-term drug addiction could induce weakness in physical performance and early fatigue, which can remain even several months after rehabilitation. High muscular endurance can help the individual to continue his daily activities without feeling tiredness and weakness. Therefore, the individual's status is changed physically and mentally, which causes an increase in self-confidence [33].

In this study, change in flexibility did not differ between experimental and control groups. In contrast, Hunter et al. (2004) and Noobregag et al. (2005) found significant changes in muscular flexibility $[19,29]$. The difference between the results of those studies and our findings could be due to differences in some training variables such as type of exercise, intensity and duration of exercise, number of movements, number of repetitions, rest between sets, rest between exercises, muscle groups involved in activity, time of exercise, duration of exercise, and other factors such as subjects' age, physical condition of the subjects during the period of return to the initial state, the status and condition of the patients (patient and non-patient), the type and history of addiction, the history of activity and their individual differences. In addition to training, flexibility is influenced by factors such as age, type and stretching of muscles, joints structure [6], body type, and gender [31]. Flexibility is an important factor for physical functioning and the prevention of injury in practice and even daily activities.

In this study, changes in body composition did not differ between experimental and control groups; however, resistance training is one of the best modalities to improve body composition and increase muscle strength. Dolezal et al. (1998) evaluated the effect of 10 weeks of resistance training (3 sessions per week) on body composition of active males and found a reduction in fat percentage and fat 
weight [14]. In addition, Pollock et al. (1996) examined the impact of resistance training on body composition and found an increase in fat free mass with reduction of body fat following training [32]. The possible reasons for these differences between our findings and previous studies could be differences in training program variables and subject characteristics.

In this study, we have some limitations including the uncontrollable effect of individual differences, genetic characteristics and heritability of subjects, stress, excitement, anxiety, mental and psychological conditions during the test and measurements, the amount of motivation in performing exercises and other uncontrollable factors.

\section{Conclusions}

The findings of the present study indicated that circuittype resistance training induced gains in muscle strength, endurance and flexibility with greater elevations in serum neurotransmitters such as serotonin, dopamine, and endorphins of addicted men. It could be recommend that addicted men during rehabilitation use circuit resistance training with progressive overload of training intensity to improve performance adaptations and enhancements in neurotransmitters related to addiction. For future studies, it is suggested having a comparative study and using the present one. Also, in the future study, the mental aspect of the training protocol should be considered. Given the positive impacts of circuit resistance training on the physical performance improvement, more attention should be paid to the use of these exercises during the treatment period.

\section{Conflict of interest: Authors state no conflict of interest.}

\section{References}

1. Abbasian S., Attarzadeh Hosseine S.R., Moazami M. (2012) The effect of regular aerobic training on serum level of $\beta$-endorphin and perceived training exertion in addicts with emphasis on brain reward center. Daneshvar., 20: 41-52.

2. Alcántara-Cordero F.J., Gómez-Píriz P.T., SánchezLópez A.M., Cabeza-Ruiz R. (2020) Feasibility and reliability of a physical fitness tests battery for adults with intellectual disabilities: the SAMU DIS-FIT battery. Disabil. Health. J., 100886. DOI: 10.1016/j. dhjo.2020.100886.

3. Arazi H., Dadvand S.S. (2017) The effect of eight week aerobic training on plasma levels of serotonin and depression in addicted men to methamphetamine during rehabilitation. Alborz. Univ. Med. J., 6: 66-74. DOI: 10.18869/acadpub.aums.6.1.66.
4. Arazi H., Dadvand S.S., Tavakoli-Fard M. (2017) Neurotransmitters and cardiovascular responses to aerobic and resistance exercise in men addicted to methamphetamine. Baltic. J. Sport. Health. Sci., 3(106).

5. Banitalebi E., Faramarzi M., Nuri R., Khosrozadeh J., Ghafoorian M. (2010) Effect of exercise training on health-related physical fitness factors and blood lipids profile of former addicted persons. Braz. J. Biomotricity, 4: 190-197.

6. Beam W., Adams G. (2011) Aerobic stepping. Exercise physiology laboratory manual 6th ed. New York (NY): McGraw-Hill, 127-133.

7. Brzycki M. (1993) Strength testing - predicting a onerep max from reps-to-fatigue. Am .J. Health. Educ., 64: 88-90. DOI: 10.1080/07303084.1993.10606684.

8. Colt E.W., Wardlaw S.L., Frantz A.G. (1981) The effect of running on plasma $\beta$-endorphin. Life. Sci. J., 28: 1637-1640. DOI: 10.1016/0024-3205(81)90319-2.

9. Da Prada M., Cesura A., Launay J., Richards J. (1988) Platelets as a model for neurones? Experientia, 44: 115-126. DOI: 10.1007/BF01952193

10. Deschenes M.R., Kraemer W.J. (2002) Performance and physiologic adaptations to resistance training. Am. J. Phys. Med. Rehabil., 81(11): S3-S16.

11. Di Chiara G. (1999) Drug addiction as dopamine-dependent associative learning disorder. Eur. J. Pharmacol., 375: 13-30. DOI: 10.1016/S0014-2999(99)00372-6.

12. Dolezal B.A, Chudzynski J., Dickerson D., Mooney L., Rawson R.A., Garfinkel A., Cooper C.B. (2014) Exercise training improves heart rate variability after methamphetamine dependency. Med. Sci. Sports. Exerc., 46: 1057. DOI: 10.1249/MSS.0000000000000201.

13. Dolezal B.A., Chudzynski J., Storer T.W., Abrazado M., Penate J., Mooney L., Dickerson D., Rawson R.A., Cooper C.B. (2013) Eight weeks of exercise training improves fitness measures in methamphetamine-dependent individuals in residential treatment. J. Addict. Med., 7: 122-128. DOI: 10.1097/ADM.0b013e318282475e.

14. Dolezal B.A., Potteiger J.A. (1998) Concurrent resistance and endurance training influence basal metabolic rate in nondieting individuals. J. Appl. Physiol., 85: 695-700. DOI: 10.1152/jappl.1998.85.2.695.

15. Farrell P.A., Joyner M., Caiozzo V. (2011) ACSM's advanced exercise physiology. Wolters Kluwer Health Adis (ESP).

16. Fontes-Ribeiro C.A., Marques E., Pereira F.C., Silva A.P., Macedo T.R.A. (2011) May exercise prevent addiction? Curr. Neuropharmacol., 9: 45-48. DOI: 10.2174/157015 911795017380.

17. Fyfe J.J., Bishop D.J., Stepto N.K. (2014) Interference between concurrent resistance and endurance exercise: molecular bases and the role of individual training variables. Sports Med., 44: 743-762. DOI: 10.1007/s40279014-0162-1. 
18. George J.D., Vehrs P.R., Allsen P.E., Fellingham G.W., Fisher A.G. (1993) VO2max estimation from a submaximal 1-mile track jog for fit college-age individuals. Med. Sci. Sports. Exerc., 25: 401-406.

19. Hunter G.R., McCarthy J.P., Bamman M.M. (2004) Effects of resistance training on older adults. Sports. Med., 34: 329-348. DOI: 10.2165/00007256-20043405000005.

20. Jackson A.S., Pollock M.L. (1978) Generalized equations for predicting body density of men. Br. J. Nutr., 40: 497-504. DOI: 10.1079/BJN19780152.

21. Kendler K.S., Ohlsson H., Edwards A.C., Sundquist J., Sundquist K. (2017) A developmental etiological model for drug abuse in men. Drug Alcohol Depend., 179: 220-228.

22. Kenney W.L., Wilmore J.H., Costill D.L. (2018) Physiology of Sport and Exercise. Human Kinetics.

23. Khalatbari J., Salimynezhad S. (2013) The Effect of Relaxation on Premenstrual Syndrome in Dormitory Students of Azad Tonekabon University of Iran. Procedia. Soc. Behav. Sci., 84: 1580-1584. DOI: 10.1016/j. sbspro.2013.06.792.

24. Lynch W.J., Peterson A.B., Sanchez V., Abel J., Smith M.A. (2013) Exercise as a novel treatment for drug addiction: a neurobiological and stage-dependent hypothesis. Neurosci. Biobehav. Rev., 37: 1622-1644. DOI: 10.1016/j.neubiorev.2013.06.011.

25. Lynch W.J., Piehl K.B., Acosta G., Peterson A.B., Hemby S.E. (2010) Aerobic exercise attenuates reinstatement of cocaine-seeking behavior and associated neuroadaptations in the prefrontal cortex. Biol. Psychiatry., 68: 774-777. DOI: 10.1016/j.biopsych.2010.06.022

26. Marghmaleki V.S., Alaei H.A., Malekabadi H.A., Pilehvarian A. (2013) Effect of physical activity on symptoms of morphine addiction in rats, after and before of lesion of the mpfc area. Iran. J. Basic. Med. Sci., 16: 1091-1099.

27. Mathes W.F., Kanarek R.B. (2006) Chronic running wheel activity attenuates the antinociceptive actions of morphine and morphine-6-glucouronide administration into the periaqueductal gray in rats. Pharmacol. Biochem. Behav., 83: 578-584. DOI: 10.1016/j.pbb.2006.03.020.

28. McCann U.D., Kuwabara H., Kumar A., Palermo M., Abbey R., Brasic J., Ye W., Alexander M., Dannals R.F., Wong D.F.J.S. (2008) Persistent cognitive and dopamine transporter deficits in abstinent methamphetamine users. Synapse., 62: 91-100. DOI: 10.1002/syn.20471.

29. Noóbrega A.C., Paula K.C., Carvalho A.C.G. (2005) Interaction between resistance training and flexibility training in healthy young adults. J. Strength. Cond. Res., 19: 842-846. DOI: 10.1519/r-15934.1.

30. O’dell S.J., Galvez B.A., Ball A.J., Marshall J.F. (2012) Running wheel exercise ameliorates methamphetamineinduced damage to dopamine and serotonin terminals. Synapse., 66: 71-80. DOI: 10.1002/syn.20989.
31. Plowman S.A., Smith D.L. (2013) Exercise physiology for health fitness and performance. Lippincott Williams \& Wilkins.

32. Pollock M.L., Vincent K.R. (1996) Resistance training for health. President's Council on Physical Fitness and Sports., 2: 8 .

33. Pourmirzaei N., Shabani R., Hojjati Zidashti Z., Izaddoust F., Moayedi A. (2018) Effect of Resistance Training on the Level of Cortisol, Testosterone Hormone, and Some Body Composition and Physical Fitness Factors of Males Washed out from Methamphetamine Addiction in Rehabilitation Period. J. Rehab. Med., 7: 154-163.

34. Rahkila P., Hakala E., Salminen K., Laatikainen T. (1987) Response of plasma endorphins to running exercises in male and female endurance athletes. Med. Sci. Sports Exerc., 19: 451-455.

35. Razali A., Madon Z. (2016) Issues and challenges of drug addiction among students in Malaysia. Adv. Soc. Sci. Res. J., 3(8).

36. Robertson C.L., Ishibashi K., Chudzynski J., Mooney L.J., Rawson R.A., Dolezal B.A., London E.D. (2016) Effect of exercise training on striatal dopamine D2/D3 receptors in methamphetamine users during behavioral treatment. Neuropsychopharmacology, 41(6): 1629.

37. Sadock B.J., Sadock V.A., Levin Ze. (2007) Kaplan and Sadock's study guide and self-examination review in psychiatry. Lippincott Williams \& Wilkins.

38. Segura-Aguilar J., Kostrzewa R.M. (2004) Neurotoxins and neurotoxic species implicated in neurodegeneration. Neurotox. Res., 6: 615-630. DOI: 10.1007/BF03033456.

39. Sekine Y., Ouchi Y., Takei N., Yoshikawa E., Nakamura K., Futatsubashi M., Okada H., Minabe Y., Suzuki K., Iwata Y., et al. (2006) Brain serotonin transporter density and aggression in abstinent methamphetamine abusers. Arch. Gen. Psychiatry, 63: 90-100. DOI: 10.1001/ archpsyc.63.1.90.

40. Shirsavar M.H., Amirtash A.M., Jalali S., Koushan M., Keavanlou F., Seyedahmadi M. (2013) Comparing the effectiveness of rehabilitation methods with and without exercise on quality of life and self-steam addicts. $J$. Sabzevar. Univ. Med. Sci., 20: 292-301.

41. Smith M.A., Fronk G.E., Abel J.M., Lacy R.T., Bills S.E., Lynch W.J. (2018) Resistance exercise decreases heroin self-administration and alters gene expression in the nucleus accumbens of heroin-exposed rats. Psychopharmacology (Berl)., 235: 1245-1255. DOI: 10.1007/s00213018-4840-9.

42. Smith M.A., Lynch W.J. (2012) Exercise as a potential treatment for drug abuse: evidence from preclinical studies. Front. Psychiatry., 2: 82. DOI: 10.3389/ fpsyt.2011.00082.

43. Smith M.A., Yancey D.L. (2003) Sensitivity to the effects of opioids in rats with free access to exercise wheels: $\mu$-opioid tolerance and physical dependence. 
Psychopharmacology (Berl)., 168: 426-434. DOI: 10.1007/s00213-003-1471-5.

44. Teixeira A.M., Trevizol F., Colpo G., Garcia S.C., Charão M., Pereira R.P., Fachinetto R., Rocha J.B., Bürger M.E. (2008) Influence of chronic exercise on reserpine-induced oxidative stress in rats: behavioral and antioxidant evaluations. Pharmacol. Biochem. Behav., 88: 465-472. DOI: 10.1016/j.pbb.2007.10.004.

45. Ugarriza D.N., Klingner S., O’Brien S. (1998) Premenstrual syndrome: diagnosis and intervention. J. Nurse. Pract., 23: 40, 45, 49-52 passim.

46. Valim V., Natour J., Xiao Y., Pereira A.F.A., da Cunha Lopes B.B., Pollak D.F., Zandonade E., Russell I.J. (2013) Effects of physical exercise on serum levels of serotonin and its metabolite in fibromyalgia: a randomized pilot study. Rev. Bras. Reumatol. Engl Ed., 53: 538-541. DOI: 10.1016/j.rbre.2013.02.001.

47. Yadid G., Ahdoot-Levi H., Bareli T., Maayan R., Weizman A. (2018) Dehydroepiandrosterone and Addiction.
In Vitamins and hormones. Academic Press; 385-412. DOI: 10.1016/bs.vh.2018.04.001.

48. Zschucke E., Heinz A., Ströhle A. (2012) Exercise and physical activity in the therapy of substance use disorders. Sci. World J., DOI: 10.1100/2012/901741.

\section{Received 12.03.2020 \\ Accepted 10.06.2020}

(C) University of Physical Education, Warsaw, Poland

\section{Acknowledgments}

This study was conducted using of financial support provided by state welfare organization of Guilan in Iran (Protocol ID: 934.95.3043).

We would like to show our gratitude to participants and all individuals who support us in performing this study. 